BMC

\title{
Public Health
}

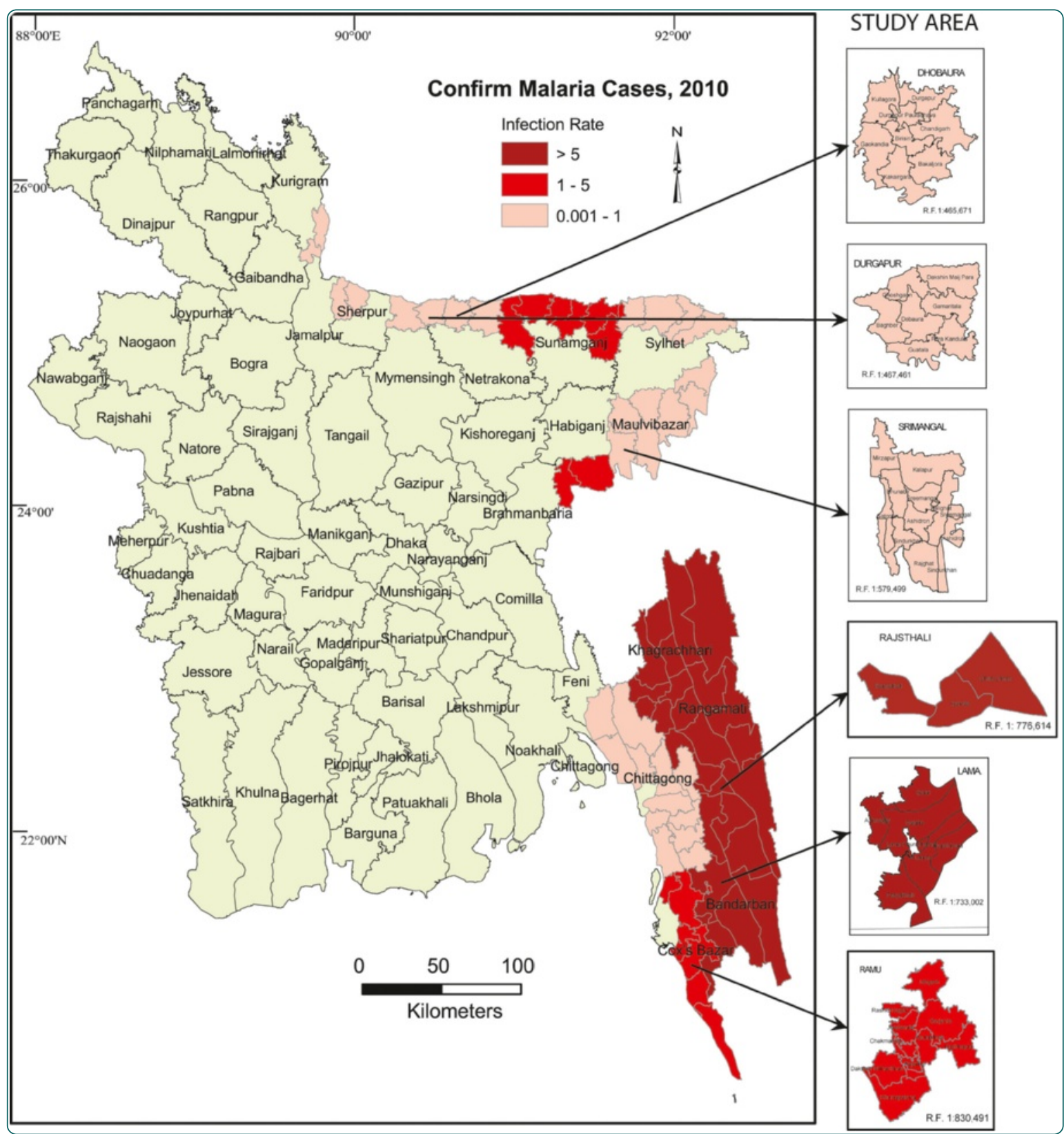

\section{Socio-demographic factors influencing knowledge, attitude and practice (KAP) regarding malaria in Bangladesh}

Bashar et al. 


\title{
Socio-demographic factors influencing knowledge, attitude and practice (KAP) regarding malaria in Bangladesh
}

\author{
Kabirul Bashar ${ }^{1 *}, \mathrm{H}$ M Al-Amin², Md Selim Reza', Muzahidul Islam${ }^{1}$ Asaduzzaman ${ }^{1}$ and Touhid Uddin Ahmed ${ }^{3}$
}

\begin{abstract}
Background: A clear understanding of the social and behavioral risk factors, and knowledge gaps, related to exposure to malaria are essential when developing guidelines and recommendations for more effective disease prevention in many malaria endemic areas of the world including Bangladesh and elsewhere in the South East Asia. To-date, the level of knowledge that human populations, residing in moderate to high malaria risk zones, have with respect to the basic pathogen transmission dynamics, risk factors for malaria or disease preventative strategies, has not been assessed in Bangladesh. The purpose of this study was to address this gap by conducting surveys of the knowledge, attitudes and practices (KAP) of people, from variable socio-demographic backgrounds, residing in selected rural malaria endemic areas in Bangladesh.
\end{abstract}

Methods: The KAP survey was conducted in portions of six different malaria endemic districts in Bangladesh from July to October 2011. The survey consisted of interviewing residence of these malaria endemic districts using a structured questionnaire and interviewers also completed observational checklists at each household where people were interviewed. The study area was further divided into two zones (1 and 2) based on differences in the physical geography and level of malaria endemicity in the two zones. Data from the questionnaires and observational checklists were analysised using Statistical Package for Social Sciences 16.0 (SPSS, Inc., Chicago, IL, USA).

Results: A total of 468 individuals from individual households were interviewed, and most respondents were female. Monthly incomes varied within and among the zones. It was found that $46.4 \%$ and $41 \%$ of respondents' family had malaria within the past one year in zones 1 and 2, respectively. Nearly $86 \%$ of the respondents did not know the exact cause of malaria or the role of Anopheles mosquitoes in the pathogen's transmission. Knowledge on malaria transmission and symptoms of the respondents of zones 1 and 2 were significantly $(p<0.01)$ different. The majority of respondents from both zones believed that bed nets were the main protective measure against malaria, but a significant relationship was not found between the use of bed net and prevalence of malaria. A significant relationship $(p<0.05)$ between level of education with malaria prevalence was found in zone 1 . There was a positive correlation between the number of family members and the prevalence of malaria. Houses with walls had a strong positive association with malaria. Approximately $50 \%$ of the households of zones 1 and 2 maintained that they suffered from malaria within the last year. A significant association $(p<0.01)$ between malaria and the possession of domestic animals in their houses was found in both zones. People who spent time outside in the evening were more likely to contract malaria than those who did not.

Conclusion: To address the shortcomings in local knowledge about malaria, health personnel working in malaria endemic areas should be trained to give more appropriate counseling in an effort to change certain deeply entrenched traditional behaviors such as spending time outdoors in the evening, improper use of bed nets and irregular use of insecticides during sleep.

\footnotetext{
* Correspondence: bkabirul@gmail.com

'Laboratory of Entomology, Department of Zoology, Jahangirnagar University, Savar, Dhaka 1342, Bangladesh

Full list of author information is available at the end of the article
} 


\section{Background}

Malaria is one of the most devastating and deadly parasitic diseases in the world. It continues to be a serious public health problem in South-East Asian countries including Bangladesh [1]. It is also a social and economic burden that creates a significant barrier to economic development. For example, over a quarter of family income can be absorbed in the cost of malaria treatment, quite apart from the cost of prevention or the opportunity cost of labor lost to illness. Malaria also prevents investment and tourism into new regions, further hampering economic development [2].

About 33.6\% of the total population in Bangladesh is at risk of malaria and the majority of cases are reported in 13 of 64 districts in the country (Figure 1) [1]. Anopheles baimaii Sallum and Peyton, 2005 (dirus D), An. minimuss.l. Theobald, 2001, An. philippinensis Ludlow, 1902, and $A n$. sundaicus (Rodenwaldt, 1925) are considered as primary malaria vectors in Bangladesh. All four species have been reported as malaria vectors in hilly forested areas of the country while only $A n$. philippinensis appears to be a vector for malaria in the lowlands or plain portion of Bangladesh [3]. Focal outbreaks of malaria are periodically reported; however, the response to these outbreaks is usually inadequate. Malaria cases are grossly under-reported due to inadequate surveillance and information dissemination systems in Bangladesh though the situation has improved in the last few years mainly because of efforts by some non-government organizations (NGOs). According to the World Health organization [1] malaria cases are presently coming down in Bangladesh though the rate of decline in morbidity could be improved.

Current malaria control strategies in Bangladesh consist of: diagnosis and treatment of clinical cases and the promotion of use of insecticide treated nets (ITNs) or long lasting insecticide-treated nets (LLINs) [4]. The use of ITNs/LLINs is the major recommendation made by the WHO to prevent malaria [5]. To achieve its goal, the government of Bangladesh with the assistance of several NGOs have undertaken several initiatives in the

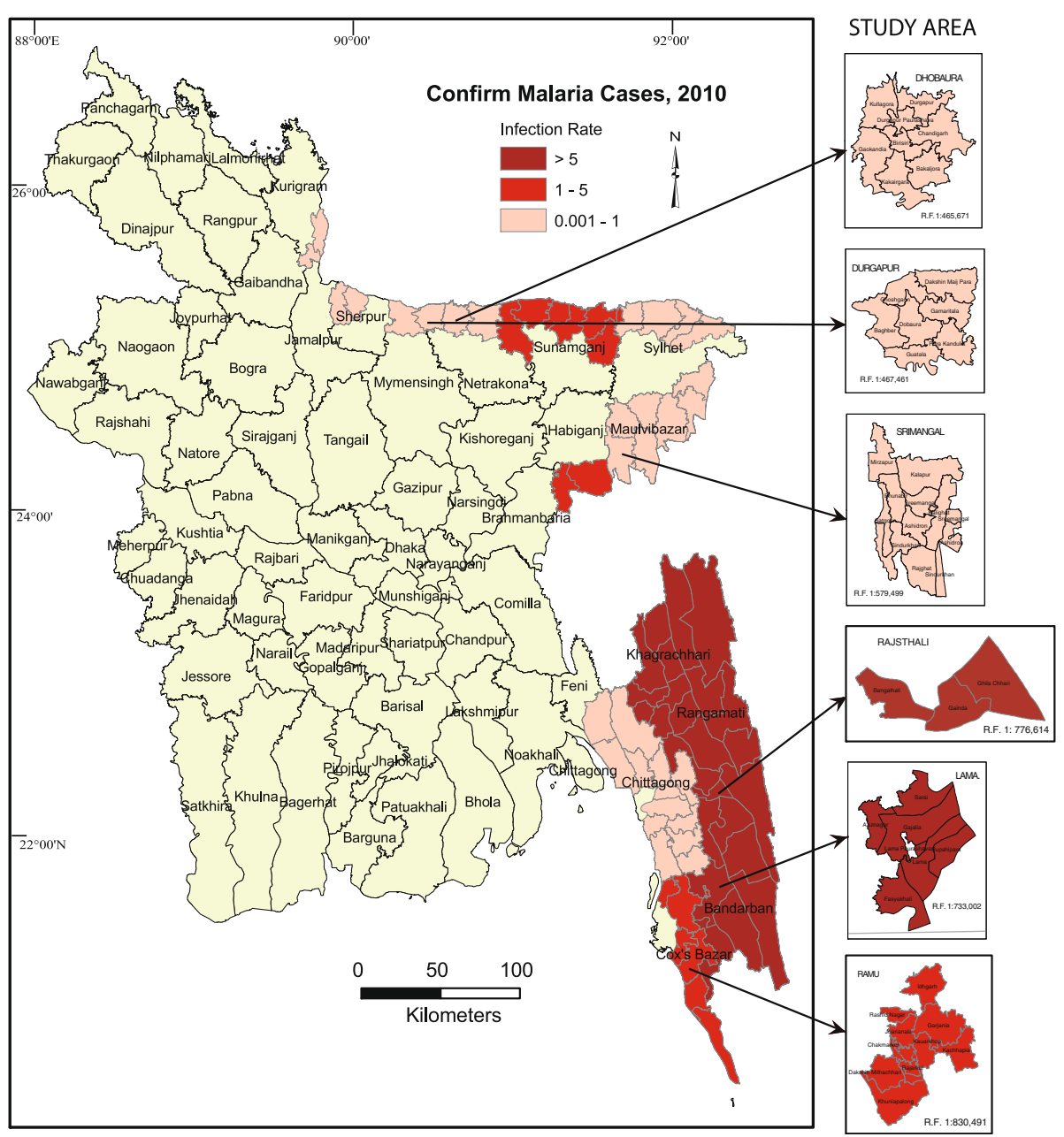

Figure 1 Study areas and malaria prevalence in Bangladesh. 
malaria endemic regions of Bangladesh and these include: the use of rapid diagnostic tests, wide spread distribution of free ITNs/LLINs, retreatment of used bed nets, distribution of free drug to treat the symptoms of malaria and training for local health assistants. Training materials for health assistance where designed to allow local health assistants to manage uncomplicated malaria cases, provide appropriated advice to families regarding case reporting and proper use of ITNs/LLINs. In a developing country like Bangladesh, malaria has the potentiality to cause great morbidity and mortality and occasional outbreaks. Plasmodium falciparum and $P$. vivax are the key parasites in Bangladesh [6,7] although sporadic cases of $P$. malariae and $P$. ovale have also been reported recently $[8,9]$. Plasmodium falciparum is the dominant parasite and accounts for $93 \%$ of the malaria cases in the country [10]. Despite the magnitude of the problem, little documented evidence exists regarding the current knowledge, attitude and practices (KAP) of the local population as it relates to malaria and its prevention and control. Given this void, the present study was conducted to assess the current level of knowledge about malaria, its mode of transmission, sign and symptoms of disease, and prevention techniques, within the human populations residing in different malaria endemic areas of Bangladesh. The objectives of the study were to assess how different socio-demographic factors impact current patterns of knowledge and how this might influence up-take of measures to prevent or control malaria.

\section{Methods}

\section{Survey areas}

The survey was conducted in portions of six different malaria endemic districts in Bangladesh from July to October 2011. The survey consisted of interviews using a structured questionnaire and the interviewer also completed an observational checklist for each household. Households were randomly selected and sample sizes of each district were fixed on the basis of the population of the areas and the anticipated regional prevalence of malaria. The study area was divided in two zones (1 and 2) on the basis of prevalence of malaria and the physical geography of the study area. Zone 1 (4 districts) is the hilly and highly malaria endemic zone while Zone 2 ( 2 districts) is the lowlands or plains habitat with low malaria endemicity. Zone 1 includes Lama upazilla (sub-district) of Bandarban, Ramu of Cox's Bazar, Rajhsthali of Rangamati, and Srimangal of Moulvibazar districts. Zone 2 consisted of Durgapur of Netrokona and Dhobaura of Mymensingh districts (Figure 1 and Table 1). The villages of Lama (Figure 2) and Ramu were inhabited by 1,206 and 1,386 people, respectively comprising both tribal and non-tribal families (Figure 3). Major parts of Lama and Ramu were vegetated by secondary forest with interspersed rubber
Table 1 Number of respondents and malaria cases in different malaria endemic region of Bangladesh

\begin{tabular}{llccc}
\hline Zone & Survey area & $\begin{array}{c}\text { Number of } \\
\text { respondents }\end{array}$ & \multicolumn{2}{c}{ Malaria cases } \\
\cline { 3 - 5 } & & Number & $\%$ \\
\hline 1 & Bandarban & 499 & 101 & 50.75 \\
& Cox's Bazar & 53 & 11 & 27.50 \\
& Rangamati & 12 & 22.64 \\
& Moulvibazar & 72 & 45 & 62.50 \\
\hline 2 & Sub-total & 364 & 169 & 46.43 \\
\hline & Netrokona & 53 & 17 & 32.08 \\
& Maymenshing & 51 & 24 & 47.10 \\
\hline & Sub-total & 104 & 41 & 39.42 \\
\hline & Total & $\mathbf{4 6 8}$ & $\mathbf{2 1 0}$ & $\mathbf{4 4 . 8 7}$ \\
\hline
\end{tabular}

plantations. The study area of Rajasthali had both a tribal and non-tribal population consisting of 997 people (50.3\% male), living within 122 households. The survey was made in Lawachara, Magurchara, Husnabad tea estates (Figure 4) and BTRI (Figure 5) in Moulvibazar district. Almost all the laborers of these tea estates were brought from Orissa state of India during British rule. These sites consist of tea gardens, semi-evergreen coniferous forests and mixed deciduous forests [11]. Survey was also conducted in Durgapur of Netrokona and in Dhobaura of Mymenshing district where some tribal people also live. Both of these districts were within similar climatic zones with foothills, plains and undulating land and densely vegetated by secondary forest. Geographical positions of the surveyed households were recorded using handheld global positioning system (GPS-Garmin Oregon 550). ArcView GIS 3.3 and Arc GIS 9.2 software were used to map the distribution of the households where interviews were conducted.

\section{Sample size}

In this survey, a total of 468 individuals from individual households were interviewed. The largest number of respondents $(n=364)$ were interviewed from four malaria prone districts (zone 1). The remainder of the respondents interviewed lived within the two low malaria endemic districts bordering Meghalaya state of India (Table 1). Sample size of zone 2 was small because of low prevalence of malaria.

\section{Ethical approval}

Ethics approval and authorization was obtained from the ethical committee of Jahangirnagar University, Bangladesh. Before data collection, each participant was clearly informed about the objectives of the study and verbal permission from the head of each household was obtained. Verbal consent was also obatin from the villagers' to capture and publish the interview photographs. 


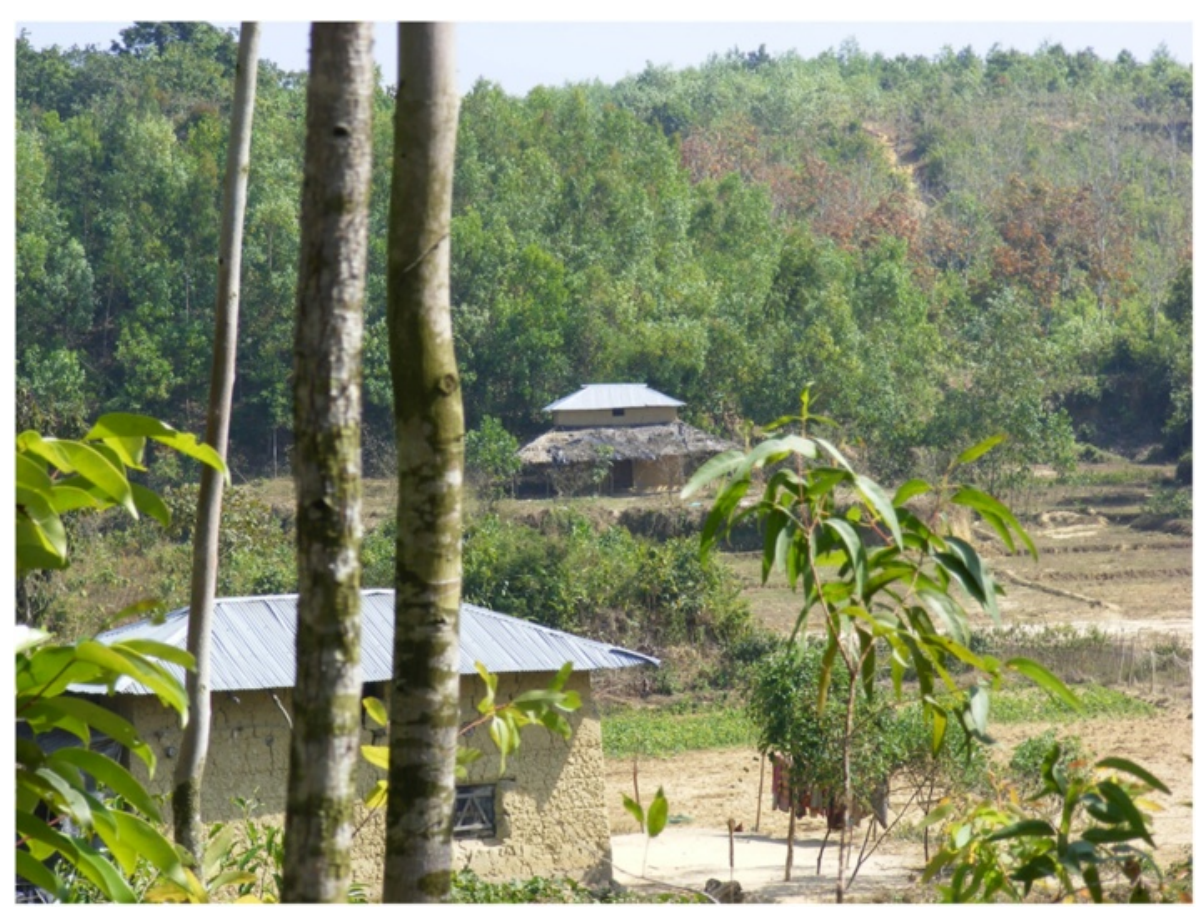

Figure 2 Pattern of the houses in Lama, Bandarban.

\section{Data collection}

Households and members to be interviewed were randomly selected. The interviewers recorded the address of the interview and type of construction of the house then selected the person to be interviewed. After obtaining verbal consent, questions were asked related to: socio-demographic features of the household members, knowledge and practices regarding malaria prevention and control, treatment-seeking behavior and use of antimalarial drugs. Selected observations related to household construction were also collected using the observational checklist. In order to minimize potential biases and to improve participant understanding the questionnaire was prepared

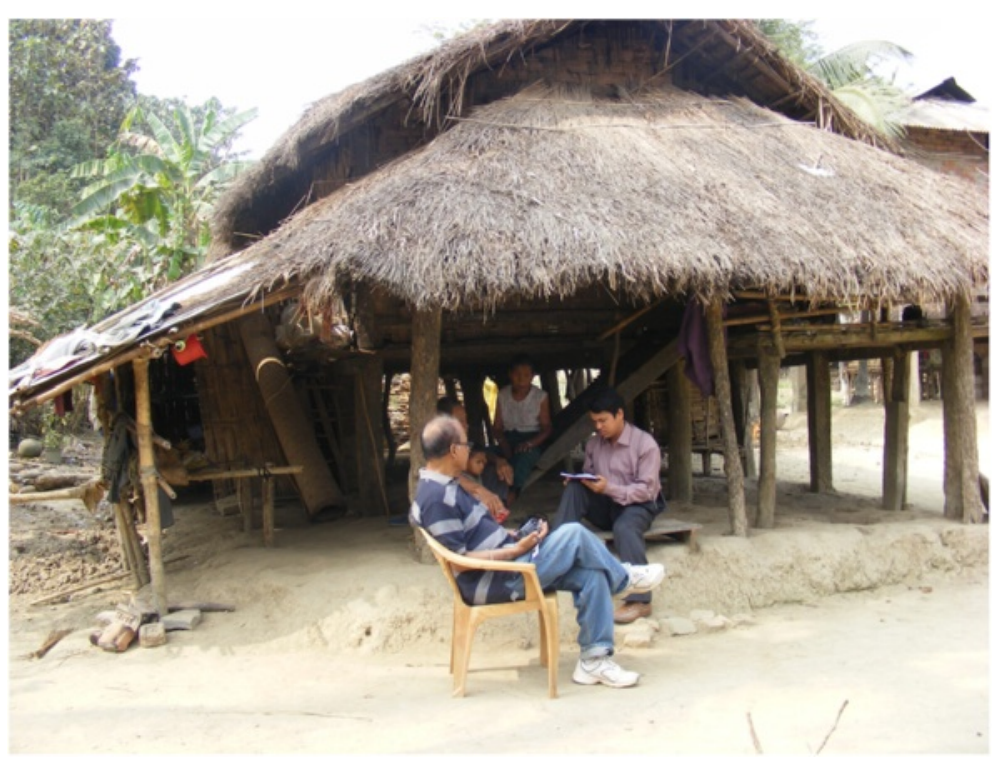

Figure 3 Interviews with a tribal family in Bandarban. 


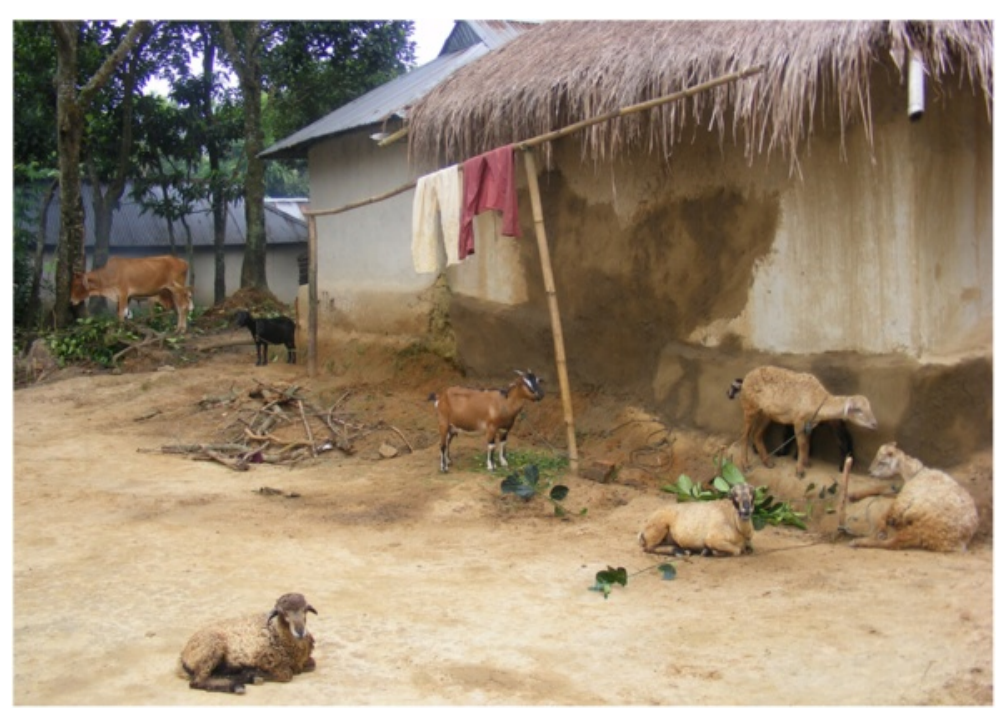

Figure 4 Respondent houses with domestic animal in Srimangal.

in English but translated and provided in the local language 'Bangla'.

\section{Data analysis}

Data analysis was done using Statistical Package for Social Sciences 16.0 (SPSS, Inc., Chicago, IL, USA). Each question was analyzed individually. Statistical relationships were sought between malaria prevalence and selected sociodemographic conditions and practices of the respondents and statistical analysis was conducted only with those families who had malaria within the last year. Results were recorded as frequencies, chi-square and $p$-values. For all purposes, $p$-value of 0.05 was considered as the level of significance.

\section{Results}

The outcomes of the questionnaire are grouped by broad category to facilitate discussion and are as follows:

\section{Demographic characteristics of the respondents}

Most of the respondents were female as adult male members were not within the household when the interviews were conducted (primarily during the daylight hours). We interviewed 220 (60.4\%) and 34 (32.7\%) female in zone

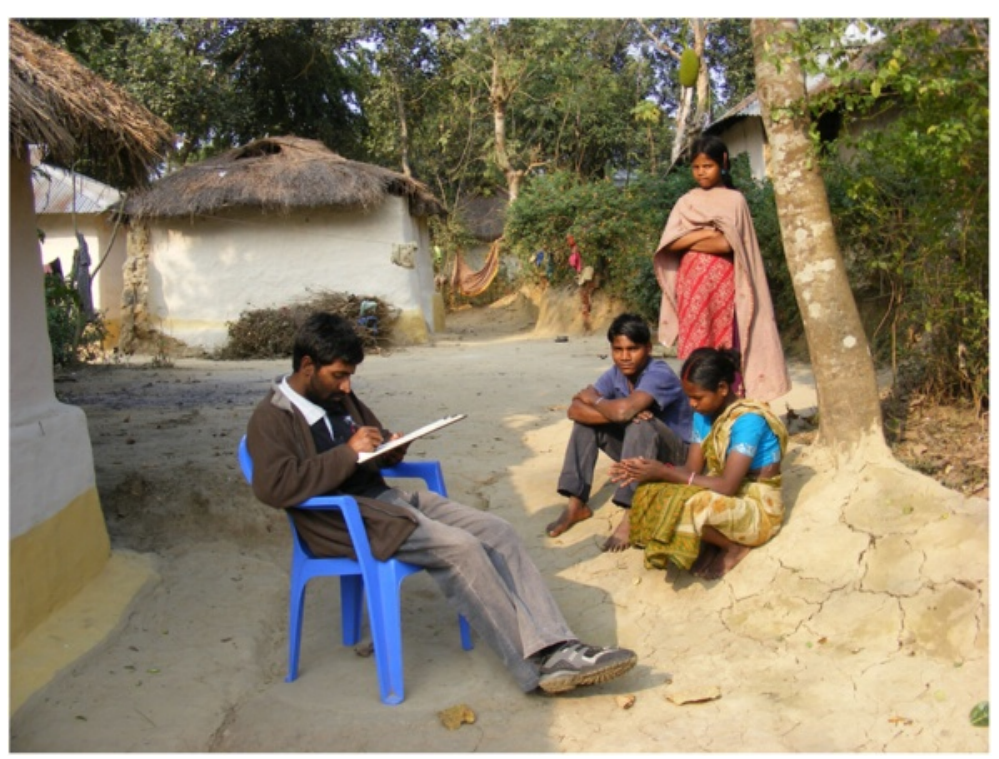

Figure 5 Household interviews in BTRI. 
1 and zone 2, respectively (Table 1 ). The majority of the respondents were 25-36 years of age in zone 1 but large numbers of respondents from zone 2 were comparatively older. Approximately $78 \%$ of the respondents were married. Large portions of the rural population surveyed were illiterate. Only $17 \%$ reported completing a secondary education in zone 1 and 2. Most of the respondents (both males and females) were involved in some kinds of agricultural work (i.e., most were farmers). More than 22\% of the individuals worked from their own homes and the majority of these individuals were females. From 11 to $18 \%$ of the respondents were unemployed in both the zones. Most of the respondents were Muslim (50.9\%), followed by Buddhist (23.7\%), Christian (20.9\%) and Hindu (4.5\%). Most households consisted of families with fewer than 6 members but more than a third had 6-10 family members sharing one household. Nearly $56 \%$ of the respondents from both zones were tribal ethnic community. Monthly incomes varied between the households in the two zones and in zone 1 more than $52 \%$ of the housed holds had a monthly income between $\$ 70$ 140 while in zone 2 more than $78 \%$ of the households earned this much monthly. A total of $46.4 \%$ and $39.4 \%$ of the respondents' family had malaria within the past year in zone 1 and zone 2, respectively (Table 2). Almost 9.8\% of the respondents reported that they had experienced about of malaria fever one month prior to the survey while $7.7 \%$ and $12 \%$ reported fever, likely due to malaria, within the last three and six months, respectively.

\section{Malaria awareness and practices}

Awareness of the mechanisms of malaria transmission and measures to prevent infection was variable among the respondents from the different zones. More than $70 \%$ of the respondents knew that malaria is acquired from the bite of a mosquito; however, a reasonable proportion of people in zone $2(13.5 \%)$ believed that malaria was contracted because of a lack of cleanliness. Only a small proportion of respondents knew that mosquitoes acquired the infection from an infected human and more respondents in zone 2 were aware of this than in zone 1 (Table 3). Increased knowledge in zone 2 may reflect the higher level of education in this zone. Nearly $86 \%$ of people did not know the exact cause of malaria and the role of anophelines in the transmission of this disease. Knowledge about the transmission cycle increased uniformly with years of schooling. The majority of the respondents in both the zones reported 'fever with rigor' as the most common symptom of malaria. Knowledge of modes of malaria transmission and its symptoms were significantly $(p<0.01)$ different between the respondents from zones 1 and 2 (Table 3 ). The respondents from both zones had diverse knowledge on the preventive measures against malaria. Although
Table 2 Demographic characteristics of the respondents

\begin{tabular}{|c|c|c|c|c|c|}
\hline \multirow[b]{2}{*}{ Characteristics } & \multicolumn{2}{|c|}{ Zone 1} & \multicolumn{2}{|c|}{ Zone 2} & \multirow[t]{2}{*}{$p$-value } \\
\hline & Number & $\%$ & Number & $\%$ & \\
\hline \multicolumn{6}{|l|}{ a) Gender } \\
\hline Male & 144 & 39.6 & 70 & 67.3 & 0.00 \\
\hline Female & 220 & 60.4 & 34 & 32.7 & \\
\hline b) Age & & & & & 0.05 \\
\hline$<13$ & 8 & 2.2 & 2 & 1.9 & \\
\hline $13-24$ & 52 & 14.3 & 15 & 14.4 & \\
\hline $25-36$ & 153 & 42.0 & 28 & 26.9 & \\
\hline $37-48$ & 79 & 21.7 & 28 & 26.9 & \\
\hline$>48$ & 72 & 19.8 & 31 & 29.8 & \\
\hline \multicolumn{6}{|l|}{ c) Educational level } \\
\hline No formal education & 144 & 39.6 & 26 & 25.0 & 0.01 \\
\hline Primary & 115 & 31.6 & 53 & 51.0 & \\
\hline Secondary & 62 & 17.0 & 18 & 17.2 & \\
\hline Tertiary & 43 & 11.8 & 7 & 6.8 & \\
\hline \multicolumn{6}{|l|}{ d) Occupation } \\
\hline Unemployed & 41 & 11.3 & 19 & 18.3 & ns \\
\hline Farmer & 112 & 30.8 & 33 & 31.7 & \\
\hline Daily labor & 38 & 10.4 & 9 & 8.7 & \\
\hline Service & 22 & 6.0 & 6 & 5.8 & \\
\hline Business & 49 & 13.5 & 4 & 3.8 & \\
\hline Technician & 1 & 0.3 & 2 & 1.9 & \\
\hline House work & 83 & 22.8 & 24 & 23.1 & \\
\hline Student & 17 & 4.7 & 7 & 6.7 & \\
\hline \multicolumn{6}{|l|}{ e) Tribe } \\
\hline No & 236 & 64.8 & 27 & 26.0 & 0.00 \\
\hline Yes & 128 & 35.2 & 77 & 74.0 & \\
\hline \multicolumn{6}{|l|}{ f) No. of family member } \\
\hline$<6$ & 210 & 57.7 & 65 & 62.5 & ns \\
\hline $6-10$ & 145 & 39.8 & 37 & 35.6 & \\
\hline$>10$ & 9 & 2.5 & 2 & 1.9 & \\
\hline \multicolumn{6}{|l|}{ g) Monthly income } \\
\hline$<70$ US\$ & 95 & 26.1 & 14 & 13.5 & 0.00 \\
\hline 70-140 US\$ & 190 & 52.2 & 82 & 78.8 & \\
\hline $141-280$ US\$ & 59 & 16.2 & 8 & 7.7 & \\
\hline$>280$ US\$ & 20 & 5.5 & 0 & 0.00 & \\
\hline
\end{tabular}

$\mathrm{ns}=$ not statistically significant.

it was observed that coil or aerosols were common in the households, people from both zones did not know that these would be effective to prevent malaria but rather used them to control nuisance mosquitoes in their homes. The majority of people from both zones believed that bed nets were the main protective measure against malaria. However, only a small portion of people from zone 1 (19.5\%) mentioned that ITNs/LLINs can 
Table 3 Awareness and practices of the respondents regarding malaria

\begin{tabular}{|c|c|c|c|c|c|}
\hline \multirow[t]{2}{*}{ Characteristics } & \multicolumn{2}{|c|}{ Zone 1} & \multicolumn{2}{|c|}{ Zone 2} & \multirow[t]{2}{*}{$p$-value } \\
\hline & Number & $\%$ & Number & $\%$ & \\
\hline \multicolumn{6}{|l|}{ a) Someone gets malaria from } \\
\hline Mosquito bites & 282 & 77.5 & 67 & 64.4 & \multirow[t]{4}{*}{0.00} \\
\hline Fly/insect bites & 6 & 1.6 & 6 & 5.8 & \\
\hline Lack of cleanliness & 14 & 3.8 & 14 & 13.5 & \\
\hline Other & 62 & 17.0 & 17 & 16.3 & \\
\hline \multicolumn{6}{|l|}{ b) Malaria is transmitted by } \\
\hline Bites from any mosquito & 211 & 58.0 & 46 & 44.2 & \multirow[t]{4}{*}{0.00} \\
\hline Bites from a a mosquito which fed upon a malaria patient & 41 & 11.3 & 24 & 23.1 & \\
\hline Other & 19 & 5.2 & 0 & 0.0 & \\
\hline Don't know & 93 & 25.5 & 34 & 32.7 & \\
\hline \multicolumn{6}{|l|}{ c) Symptoms of malaria } \\
\hline Fever with rigor & 241 & 66.2 & 45 & 43.3 & \multirow[t]{5}{*}{0.00} \\
\hline Intermittent fever & 40 & 11.0 & 17 & 16.3 & \\
\hline Fever with sweating & 16 & 4.4 & 9 & 8.7 & \\
\hline Other & 6 & 1.6 & 0 & 0.0 & \\
\hline Don't know & 60 & 16.5 & 33 & 31.7 & \\
\hline \multicolumn{6}{|l|}{ d) Malaria can be prevented by } \\
\hline Limiting mosquito breeding & 31 & 8.5 & 16 & 15.4 & \multirow[t]{6}{*}{ ns } \\
\hline Bed net & 168 & 46.2 & 51 & 49.0 & \\
\hline Mosquito coil/aerosol & 32 & 8.8 & 8 & 7.7 & \\
\hline ITN & 71 & 19.5 & 14 & 13.5 & \\
\hline Other & 7 & 1.9 & 0 & 0.0 & \\
\hline Don't know & 55 & 15.1 & 15 & 14.4 & \\
\hline \multicolumn{6}{|l|}{ e) Malaria treatment provided by } \\
\hline NGO & 277 & 76.1 & 94 & 90.4 & \multirow[t]{4}{*}{0.01} \\
\hline Gov. hospital & 34 & 9.3 & 10 & 9.6 & \\
\hline Village doctor & 18 & 4.9 & 0 & 0.0 & \\
\hline Drug seller & 35 & 9.6 & 0 & 0.0 & \\
\hline \multicolumn{6}{|l|}{ f) Enter the house previous night } \\
\hline$<6 \mathrm{pm}$ & 196 & 53.8 & 26 & 25.0 & \multirow[t]{3}{*}{0.00} \\
\hline $6 p m-9 p m$ & 158 & 43.4 & 76 & 73.1 & \\
\hline$>9 \mathrm{pm}$ & 10 & 2.7 & 2 & 1.9 & \\
\hline \multicolumn{6}{|l|}{ g) Spent time last afternoon } \\
\hline Inside & 154 & 42.3 & 20 & 19.2 & \multirow[t]{4}{*}{0.00} \\
\hline Outside & 195 & 53.6 & 78 & 75.0 & \\
\hline Market & 10 & 2.7 & 1 & 1.0 & \\
\hline Tea stall & 5 & 1.4 & 5 & 4.8 & \\
\hline \multicolumn{6}{|l|}{ h) Spent most of the night time } \\
\hline Inside & 356 & 97.8 & 104 & 100.0 & \multirow[t]{2}{*}{ ns } \\
\hline Outside & 7 & 1.9 & 0 & 0.0 & \\
\hline
\end{tabular}

$\mathrm{ns}=$ not statistically significant. 
prevent malaria even though these nets were provided to them, specifically for that purpose since 2007 [10]. It was observed that information, education and communication (IEC) activities regarding the use of ITN/LLIN was poor. Not surprisingly, only a small proportion of people from either zone reported that managing mosquito breeding places was a good preventive measure. Most of the respondents of both zones reported that NGOs provided malaria treatment in their areas. None of the respondents from zone 2 sought treatment from the village doctor or drug sellers while nearly $15 \%$ of the respondents from zone 1used these sources when seeking treatment. Close to $100 \%$ of the respondents reported that they sleep inside at night but more than $50 \%$ people returned home after sunset. More than $53 \%$ of people from both zones stayed outside in the afternoon and about $5 \%$ of them spent evening hours at nearby tea stalls or market places (Table 3).

Association of malaria with socio demographic conditions The highest proportion of respondents with malaria lived in Moulvibazar and Bandarban districts. Significant differences $(p<0.01)$ were observed in the prevalence of malaria among the six study districts. Level of education was an important variable with respect to malaria and awareness of the disease. For example, level of education was significantly related to of prevalence of malaria $(p<0.05)$ in zone 1 but not zone 2. Occupation and religious affiliation (data not shown) did not appear to be important with respect to prevalence of malaria. However, the number of family members residing within a household did significantly influence malaria prevalence. There was a positive correlation between number of family members per household and prevalence of malaria. Households with more than 6 family members had a higher prevalence of malaria. A significant relationship with average monthly income and prevalence of malaria was observed in zone 1 but not zone 2 . Similarly, a strong association $(p<0.01)$ was observed between the type of materials used in the partitions of the houses and prevalence of malaria in only zone 1. The majority of the household where malaria cases resided were constructed with mud walls. Likewise, more than $75 \%$ of the houses had tin roofs and partitions with floor made of mud. Almost all of the malaria cases resided in homes with tin or straw/thatched roofs and only 3 cases of malaria lived within homes built from bricks. Significant associations between the occurrence of malaria and type of roof or floor were not observed (Table 4), and this was not surprising since mosquitoes tend to rest on walls and not on floor.

Association of malaria with practices of the respondents In total $47 \%$ and $40 \%$ of the respondents' reported that they slept under a bed net regularly in zones 1 and 2, respectively, but still a high proportion of respondents contracted malaria. This might be explained by improper or infrequent use of bed nets. We observed that people sometimes sleep at night in open spaces (and not under a bed net) during periods of hot weather. Although most people believe that use of mosquito nets prevent malaria transmission but significant relation $(p>0.05)$ between malaria cases and use of bed net was not found. Residents of zone 1 did use insecticides (especially coils) more frequently than people from zone 2 . It is possible that people in zone 1 suffer from malaria more than area 2, which prompts them to used insecticides more frequently. Although a reasonable proportion of villagers from both zones used insecticides in their houses for mosquito control the effect of insecticide use on prevalence of malaria was not significant $(p>0.05)$ in either zone. Interestingly, the majority of malaria cases were observed in residents living in homes with domestic animals (e.g., cattle, goat, sheep, dog, chicken and ducks). Approximately 50\% of the households in zone 1 and 2 who had domestic animals suffered from malaria within the last year and this relationship was statistically significant in both zones $(p<0.01)$ (Table 5). Spending a portion of the evening at outdoor meeting places was a regular practice for most of the people who acquired malaria and the majority of them returned to their houses before $9 \mathrm{pm}$. A strong statistical relationship between malaria prevalence $(p=<0.01)$ and the time when people returned home was observed in both study zones (Table 5). It appears that malaria transmission is more closely associated with the places where the people spent time after sunset than other factors.

\section{Discussion}

Based on the outcomes of this survey, almost all of the respondents were familiar with some aspects of malaria, NGO health workers were one of the main sources of information and this illustrates that NGOs are frequently in contact with villagers. The majority of the respondents were aware of the symptoms of malaria. Most were able to recognize 'fever with rigor' as the main symptom of malaria and again this was probably due to the educational messages delivered by NGO health workers. Recognition of the early symptoms of malaria is key to seeking early treatment. Sadly, about 25\% the respondent did not know how malaria is acquired and few were aware of the modes of transmission or even the role of mosquitoes in transmission. Even when people were aware that mosquitoes were the vector of malaria, few were aware that mosquitoes became infected by feeding upon a person with malaria. This lack of knowledge was similar between the two study zones. Nearly $32 \%$ of the respondents from zone 2 were unaware about the symptoms of malaria. It may be that people from zone 2 are less familiar with the symptoms because fewer people acquire infection on an annual basis. 
Table 4 Association of malaria with the socio demographic conditions of the respondents

\begin{tabular}{|c|c|c|c|c|c|c|}
\hline \multirow[t]{2}{*}{ Variables and responses } & \multicolumn{2}{|c|}{ Malaria cases (Zone 1) } & \multirow[t]{2}{*}{$p$-value } & \multicolumn{2}{|c|}{ Malaria cases (Zone 2) } & \multirow[t]{2}{*}{$p$-value } \\
\hline & Number & $\%$ & & Number & $\%$ & \\
\hline \multicolumn{7}{|l|}{ a) Tribe } \\
\hline No & 111 & 47.03 & ns & 7 & 25.93 & ns \\
\hline Yes & 58 & 45.31 & & 34 & 44.16 & \\
\hline \multicolumn{7}{|l|}{ b) Educational level } \\
\hline No formal education & 71 & 42.51 & 0.02 & 10 & 38.46 & ns \\
\hline Primary & 60 & 52.17 & & 30 & 56.60 & \\
\hline Secondary & 37 & 50.68 & & 13 & 61.90 & \\
\hline Tertiary & 1 & 11.11 & & 0 & 0.00 & \\
\hline \multicolumn{7}{|l|}{ c) Occupation } \\
\hline Unemployed & 25 & 60.98 & ns & 6 & 31.58 & ns \\
\hline Farmer & 51 & 45.54 & & 15 & 45.45 & \\
\hline Daily labour & 22 & 57.89 & & 4 & 44.44 & \\
\hline Service & 8 & 36.36 & & 1 & 16.67 & \\
\hline Business & 22 & 44.90 & & 1 & 25.00 & \\
\hline House work & 30 & 36.14 & & 10 & 41.67 & \\
\hline Student & 10 & 58.82 & & 4 & 57.14 & \\
\hline \multicolumn{7}{|l|}{ d) Family member } \\
\hline$<6$ & 86 & 40.95 & 0.05 & 20 & 30.77 & 0.03 \\
\hline $6-10$ & 78 & 53.79 & & 19 & 51.35 & \\
\hline$>10$ & 5 & 55.56 & & 2 & 100.00 & \\
\hline \multicolumn{7}{|c|}{ e) Monthly income of the family } \\
\hline$<70$ US\$ & 52 & 54.74 & 0.05 & 6 & 42.86 & ns \\
\hline $70-140$ US\$ & 75 & 39.47 & & 33 & 40.24 & \\
\hline $141-280$ US\$ & 27 & 45.76 & & 2 & 25.00 & \\
\hline$>280$ US\$ & 15 & 75.00 & & 0 & 0.00 & \\
\hline \multicolumn{7}{|l|}{ f) Roof of the house } \\
\hline Straw/thatch & 38 & 51.35 & ns & 17 & 48.57 & \\
\hline Tin & 130 & 45.14 & & 22 & 32.84 & ns \\
\hline Concrete/Cement & 1 & 50.00 & & 2 & 100.00 & \\
\hline \multicolumn{7}{|l|}{ g) Partition of the house } \\
\hline Jute stick/bamboo & 20 & 31.25 & 0.01 & 14 & 53.85 & ns \\
\hline Tin & 3 & 20.00 & & 5 & 25.00 & \\
\hline Concrete/Cement & 25 & 53.19 & & 4 & 25.00 & \\
\hline Mud & 121 & 51.27 & & 18 & 42.86 & \\
\hline \multicolumn{7}{|l|}{ h) Floor of the house } \\
\hline Mud & 141 & 47.64 & ns & 34 & 43.04 & ns \\
\hline Cemented & 10 & 38.46 & & 7 & 28.00 & \\
\hline Semi-Cemented & 13 & 54.17 & & 0 & 0 & \\
\hline Other & 5 & 27.78 & & 0 & 0 & \\
\hline
\end{tabular}

$\mathrm{ns}=$ not statistically significant. 
Table 5 Association of malaria with practices of the respondents

\begin{tabular}{|c|c|c|c|c|c|c|}
\hline \multirow[t]{2}{*}{ Variables and responses } & \multicolumn{2}{|c|}{ Malaria cases (Zone 1) } & \multirow[t]{2}{*}{$p$-value } & \multicolumn{2}{|c|}{ Malaria cases (Zone 2) } & \multirow[t]{2}{*}{$p$-value } \\
\hline & Number & $\%$ & & Number & $\%$ & \\
\hline \multicolumn{7}{|l|}{ a) Full family use of bed nets } \\
\hline No & 12 & 37.50 & ns & 3 & 37.50 & ns \\
\hline Yes & 157 & 47.29 & & 38 & 40.00 & \\
\hline \multicolumn{7}{|l|}{ b) Use insecticides } \\
\hline No & 98 & 43.75 & ns & 22 & 48.89 & ns \\
\hline Yes & 71 & 50.71 & & 19 & 32.20 & \\
\hline \multicolumn{7}{|l|}{ c) Domestic animals present } \\
\hline No & 51 & 38.35 & 0.02 & 14 & 29.17 & 0.04 \\
\hline Yes & 118 & 51.53 & & 27 & 48.21 & \\
\hline \multicolumn{7}{|l|}{ d) Usually enter the house } \\
\hline$<6 \mathrm{pm}$ & 102 & 52.04 & 0.03 & 15 & 57.69 & 0.05 \\
\hline $6 p m-9 p m$ & 65 & 41.14 & & 26 & 34.21 & \\
\hline$>9 \mathrm{pm}$ & 2 & 20.00 & & 0 & 0.00 & \\
\hline \multicolumn{7}{|c|}{ e) Usually spent time in the afternoon hours } \\
\hline Inside & 83 & 53.90 & 0.03 & 11 & 55.00 & ns \\
\hline Outside & 77 & 39.49 & & 28 & 35.90 & \\
\hline Market & 5 & 50.00 & & 0 & 0.00 & \\
\hline Tea stall & 4 & 80.00 & & 2 & 40.00 & \\
\hline
\end{tabular}

$\mathrm{ns}=$ not statistically significant.

Economics also played a role in malaria in this study. For example, poor families had a higher prevalence of malaria and this is likely influenced by construction materials used in their homes. As has been reported by others [12], in malaria endemic areas the risk of infection is higher in poorly built houses than in well-built ones. In southern Sri Lanka, the risk of malaria was reported to be 2.5-fold higher between residents of poorly constructed houses compared to people living in houses of good construction type [13]. A similar situation between malaria prevalence and housing types were in zone 1. Malaria prevalence was also linked to family size such that large families sharing a single household tended to have a higher prevalence of malaria. This relationship may be related to the fact that large family households contain people who are generally poor, illiterate and living in poorly constructed houses. In addition, many of these individuals spent time outdoors in the late afternoon or early evening and did not sleep under a bed net.

With respect to knowledge about malaria prevention, many people were unaware of the most effective prevention methods. The lack of knowledge likely stems from a lack of IEC (Information, Education and Communication) activities in the study area.

Although NGOs were supposed to distribute ITNs to every family [14] of the study area some respondents claimed that they had yet to receive any form of bed net
(ITNS or LLINS). Many respondents mentioned that a household would receive a single net but this was not sufficient for all of their family members. Indeed, the current malaria control strategy in Bangladesh relies mainly on the use of ITNs/LLINs. For several years, this strategy has benefited from a mass campaign promotion [14]. Before the introduction of treated nets, Bangladesh reported as about 50,000 confirmed malaria cases and 450 malaria deaths annually [14]. After the distribution of ITNs/LLINs, mortality came down from 450 to as low as 37 in the year $2010[10,14]$. Interestingly, in the present study, we did not find a significant effect of bed nets to reduce malaria in areas where ITNs/LLINs were distributed. In contrast, some African researcher reported that rates of malaria transmission and subsequent morbidity were lowered to $50 \%$ when ITNs/LLINs were widely distributed [15-17]. It may be that the malaria vectors in Bangladesh have developed resistance to the insecticides used in the treated nets. Unpublished reports of DG health of Bangladesh that as few as 20\% of malaria vector were killed in recently performed bioassays (Personal communication with Dr. Chowdhury). Antonio-Nkondjio reported that An. gambiae populations in Cameroon have developed resistance to Deltamethrin used in treated nets [18]. A more thorough assessment of the susceptibility of mosquito vectors in Bangladesh to the active ingredients in ITNs/LLINs seems warranted Alternatively, there may be other factors that are reducing 
the efficacy of the nets including: rapid loss of insecticidal quality of the treated nets due to accumulation of dust on the nets, heat effects from cooking in the same room where the nets are stored or failure to properly wash the nets. These specific issues need additional attention in the malaria endemic area of Bangladesh.

A strong association between malaria prevalence and places where people spent time after sunset was observed in study zone 1 . Some malaria vectors in Bangladesh prefer to bite mainly outdoors [19] in the early part of night. Bashar et al. [19] reported higher HBI (Human Blood index) in outdoor-collected Anopheles mosquitoes than ones collected in-doors. Thus people who spent time outside have more chance to get malaria [19], partly because people may be bitten more frequently outdoors. The location of acquisition of malaria may be a point that needs to be emphasized in future educational materials as other researchers in Bangladesh [20] have also noted that malaria risk may occur outdoors as well as indoors.

It has been well established that if mosquito blood meals can be diverted to wild or domestic animals, which are not the reservoir host of malaria, then the number of malaria cases can be reduced in a given area [21]. This is counter to what we observed in this study, where persons who kept domestic animals, had more malaria. The present observation supports the results of Idress and Jan [22]. They reported that malaria parasite rate were greater among the children of families who kept cattle than among those who did not. In some recent studies, Plasmodium parasites were detected serologically in some zoophilic Anopheles mosquitoes in the same areas where the current study was performed [23-25]. Thus some of these zoophilic mosquito species may feed upon humans and potentially could transmit malaria $[19,25]$. Further research is needed to clarify the vector status of some of these zoophilic mosquito species.

\section{Conclusion}

In the present survey, it was clear that the majority of the respondents did not have adequate knowledge on how malaria is transmitted. Similarly, many people don't know the preventive measures to take to minimize potential exposure to malaria. This lack of knowledge is likely due to inadequate coverage with IEC activities.

Based on the results of this study, enhanced health education following the IEC system may be effective in improving the knowledge of residents within these rural communities. Health personnel working under health department and NGOs may need to be retrained in order to change certain deeply entrenched activities that put people at risk of exposure to malaria infected mosquitoes. For example, residents should be counseled to avoid spending time outdoors at peak risk periods, on the proper use of bed nets and how and when to best use insecticides in the home. Similarly, people should be notified of the potential risks of malaria (and how to minimize them) that arise when one stays outdoors after sunset. Effective malaria preventive methods should be affordable and readily available to the most vulnerable populations, as should access to treatment. Lastly, entomological surveillance should be continued and effectiveness of INTs/LLINs should be continuously evaluated in these highly malaria endemic areas of Bangladesh.

\section{Competing interests}

The authors declare that they have no competing interests.

\section{Authors' contributions}

KB designed the study. KB, HMA, MSR, MI, A and TUA performed the survey. KB analyzes the data. KB, HMA, MSR, MI, A and TUA collaborated to write the manuscript. All authors read and approved the final draft of the manuscript.

\section{Acknowledgements}

We are grateful to Kh. Md. Zulfiker Rahman, and Ms. Sagorica for helping us during the field work. Grateful thanks to Mr. Shafiul Alam, ICDDR'B for helping to design the questionnaire. Special thanks to Mr. Nasrin Sultana, Lecturer, Department of Statistics, Bangabandhu Sheikh Mujibur Rahman Agricultural University, Kh. Hasan Mahmud, Assistant Professor, Department of Geography and Environment and M. Rezaul Karim, Assistant Professor, Department of Statistics, Jahangirnagar University for valuable suggestions and help with the data analysis. Grateful thanks to Dr. Robbin Lindsay of the Public Health Agency of Canada for review and edit the manuscript. We acknowledge all of the villagers for their kind support and co-operation during the survey. This work was partially supported by RONPAKU fellowship of Japan Society for the Promotion of Science (JSPS).

\section{Author details}

${ }^{1}$ Laboratory of Entomology, Department of Zoology, Jahangirnagar University, Savar, Dhaka 1342, Bangladesh. '2Laboratory of Parasitology, Centre for Communicable Disease, International Centre for Diarrhoeal Disease Research Bangladesh, Dhaka, Bangladesh. ${ }^{3}$ Institute of Epidemiology, Disease Control \& Research (IEDCR), Mohakhali, Dhaka 1212, Bangladesh.

Received: 6 September 2012 Accepted: 13 December 2012

Published: 18 December 2012

\section{References}

1. WHO: World Malaria Report 2011. Geneva: World Health Organization; 2012. http://www.malaria.org, Accessed on 20 August, 2012.

3. Elias M, Dewan R, Ahmed R: Vectors of malaria in Bangladesh. J Prev Social Med 1982, 1:20-28.

4. Ahmed SM, Haque R, Haque U, Hossain A: Knowledge on the transmission, prevention and treatment of malaria among two endemic populations of Bangladesh and their health-seeking behavior. Malaria J 2009, 8:173.

5. WHO: Insecticide Treated Nets: A Position Statement. Geneva: World Health Organization; 2007:12.

6. Haque U, Ahmed SM, Hossain S, Huda M, Hossain A, Alam MS, Mondal D, Khan WA, Khalequzzaman M, Haque R: Malaria prevalence in endemic districts of Bangladesh. PLoS One 2009, 4(8):e6737.

7. Alam MS, Mohon AN, Mustafa S, Khan WA, Islam N, Karim MJ, Khanum H, Sullivan DJ, Haque R: Real-time PCR assay and rapid diagnostic tests for the diagnosis of clinically suspected malaria patients in Bangladesh. Malaria J 2011, 10(1):175.

8. Fuehrer HP, Starzengruber P, Swoboda P, Khan WA, Matt J, Ley B, Thriemer K, Haque R, Yunus EB, Hossain SM, et al: Indigenous Plasmodium ovale malaria in Bangladesh. AmJTrop Med Hyg 2010, 83(1):75-78.

9. Rahman W, Chotivanich K, Silamut K, Tanomsing N, Hossain A, Faiz MA, Dondorp AM, Maude RJ: Plasmodium malariae in Bangladesh. Trans R SoC Trop Med Hyg 2010, 104(1):78-80. 
10. WHO: World Malaria Report 2010. Geneva: World Health Organization; 2011.

11. Banglapedia: National Encyclopedia of Bangladesh, 2010.

12. Gamage-Mendis AC, Carter R, Mendis C, De Zoysa AP, Herath PR, Mendis $\mathrm{KN}$ : Clustering of malaria infections within an endemic population: risk of malaria associated with the type of housing construction. Am J Trop Med Hyg 1991, 45(1):77-85.

13. Gunawardena DM, Wickremasinghe AR, Muthuwatta L, Weerasingha $S$, Rajakaruna J, Senanayaka T, Kotta PK, Attanayake N, Carter R, Mendis KN: Malaria risk factors in an endemic region of Sri Lanka, and the impact and cost implications of risk factor-based interventions. Am J Trop Med Hyg 1998, 58(5):533-542.

14. Ahmed SM, Hossain S, Kabir MM, Roy S: Free distribution of insecticidal bed nets improves possession and preferential use by households and is equitable: findings from two cross-sectional surveys in thirteen malaria endemic districts of Bangladesh. Malaria J 2011, 10:357.

15. D'Alessandro U, Olaleye B, Langerock P, Aikins MK, Thomson MC, Cham MK, Greenwood BM, McGuire W, Bennett S, Cham BA: Mortality and morbidity from malaria in Gambian children after introduction of an impregnated bednet programme. Lancet 1995, 345(8948):479-483.

16. Nevill CG, Some ES, Mung'Ala VO, Muterni W, New L, Marsh K, Lengeler C, Snow RW: Insecticideâ treated bednets reduce mortality and severe morbidity from malaria among children on the Kenyan coast. Trop Med Int Health 1996, 1(2):139-146.

17. Njama D, Dorsey G, Guwatudde D, Kigonya K, Greenhouse B, Musisi S, Kamya MR: Urban malaria: primary caregiversâ knowledge, attitudes, practices and predictors of malaria incidence in a cohort of Ugandan children. Trop Med Int Health 2003, 8(8):685-692.

18. Antonio-Nkondjio C, TeneFossog B, Ndo C, MenzeDjantio B, ZebazeTogouet S, Awono-Ambene P, Costantini C, Wondji C, Ranson H: Anopheles gambiae distribution and insecticide resistance in the cities of Douala and Yaoundé@ (Cameroon): influence of urban agriculture and pollution. Malaria J 2011, 10(1):1-13.

19. Bashar K, Tuno N, Ahmed TU, Howlader AJ: Blood-feeding patterns of Anopheles mosquitoes in a malaria-endemic area of Bangladesh. Parasite Vectors 2011, 5:39.

20. Ahmed S, Khan WA, Prue CS, Khyang J, Haque R, Ram M, Sack DA, Sullivan D: Survey of Knowledge, Practice, and Coverage on Malaria in a Malariaendemic Region of Bangladesh. In 13th Annual Scientific Conference of ICDDR'B, Bangladesh. 2011. Abstract no. 327.

21. WHO: Manual on environmental management for mosquito control with special emphasis on malaria vectors. World Health Organization Offset Publication, Geneva 1982, 66:1-284.

22. Idrees M, Jan AH: Failure of Zooprophylaxis: Cattle Ownership Increase Rather than Reduce the Prevalence of Malaria in District Dir, NWFP of Pakistan. Sciences 2001, 1(2):52-54.

23. Alam MS, Chakma S, Khan WA, Glass GE, Mohon AN, Elahi R, Norris LC, Podder MP, Ahmed S, Haque R, Sack DA DJS Jr, Norris DE: Diversity of anopheline species and their Plasmodium infection status in rural Bandarban, Bangladesh. Parasite Vectors 2012, 5:150.

24. Alam M, Khan M, Chaudhury N, Deloer S, Nazib F, et al: Prevalence of anopheline species and their Plasmodium infection status in epidemicprone border areas of Bangladesh. Malaria J 2010, 9:15.

25. Bashar K, Tuno N, Ahmed TU, Howlader AJ: False positive of circumsporozoite protein (CSP)-ELISA in zoophilic anophelines in Bangladesh. Actatropica 2012, do::10.1016/j.actatropica.2012.10.004.

doi:10.1186/1471-2458-12-1084

Cite this article as: Bashar et al.: Socio-demographic factors influencing knowledge, attitude and practice (KAP) regarding malaria in Bangladesh. BMC Public Health 2012 12:1084.

\section{Submit your next manuscript to BioMed Central and take full advantage of:}

- Convenient online submission

- Thorough peer review

- No space constraints or color figure charges

- Immediate publication on acceptance

- Inclusion in PubMed, CAS, Scopus and Google Scholar

- Research which is freely available for redistribution

Submit your manuscript at www.biomedcentral.com/submit 